\title{
Doctors' Experiences of Providing Sexual and Reproductive Health Care at Catholic Hospitals in the Conflict-Affected North-West Region of Cameroon
}

Adama Awasom-Fru ( $\nabla$ awasomadama@gmail.com )

Uppsala University: Uppsala Universitet https://orcid.org/0000-0001-9008-0910

Maturin Désiré Sop Sop

UBa: University of Bamenda

Elin Larsson

$\mathrm{Kl}$ : Karolinska Institutet

Sibylle Herzig van Wees

Karolinska Institute: Karolinska Institutet

\section{Research Article}

Keywords: Sexual and reproductive health, doctor's experiences, Catholic Hospitals, Cameroon

Posted Date: January 18th, 2022

DOI: https://doi.org/10.21203/rs.3.rs-1254038/v1

License: (c) (i) This work is licensed under a Creative Commons Attribution 4.0 International License.

Read Full License 


\section{TITLE: Doctors' experiences of providing Sexual and Reproductive Health Care at Catholic Hospitals in the conflict-affected North- West Region of Cameroon}

Corresponding author

Adama Awasom-Fru, MD, Uppsala University, Department of Women and Children's Health, Sweden.

Other authors.

Maturin Désiré Sop Sop: PhD, University of Bamenda. Department of Geography

Elin Larsson, PhD, Department of Global Public Health, Department of Women and Childrens Health, Karolinska Institutet

Sibylle Herzig van Wees: PhD, Department of Global Public Health, Karolinska Institutet 


\section{Abstract}

Background: Sexual and reproductive health (SRH) care services are essential to improving the lives of women and achieving the Sustainable Development Goals. The Catholic Church is one the biggest non-governmental suppliers of health care in sub-Saharan Africa, including Cameroon but their role in providing SRH care is restricted by religious norms and values. This study explored doctors' experiences and perceptions of providing SRH care at Catholic hospitals in a conflict affected area in Cameroon.

Methods: A qualitative study was conducted using ten semi-structured interviews with general practitioners from three Catholic hospitals in North-West region in Cameroon. Qualitative coding was done with assistance from Nvivo 12.0, data was analyzed using thematic analysis.

Results: The findings are presented in three main themes. Respondents describe (1) strict rules and a broad range of challenges to providing comprehensive sexual and reproductive health care services. Nonetheless there is evidence of (2) doctors overcoming obstacles to providing sexual and reproductive healthcare through referrals, provision of care in secrecy and occasional negotiating with the hospital administration. Despite overcoming challenges, participants describe numerous examples of (3) poor sexual and reproductive health care and poor health outcomes, including avoidable deaths.

Conclusion: This study shows that understanding the intersect between religion and women's health remains important, particularly in improving access to sexual and reproductive health to vulnerable populations in conflict affected areas. It further provides insight into doctors' motivations to practicing medicine and how doctors cope and make efforts to provide care and minimize harm

Keywords; Sexual and reproductive health, doctor's experiences, Catholic Hospitals, Cameroon 


\section{Plain English Summary}

The main aim of this study was to explore doctors' experiences and perceptions of providing sexual and reproductive health care services at Catholic hospitals in a conflict affected area in Cameroon. In Cameroon, sexual, and reproductive health services are lacking, thereby contributing to a very high maternal mortality rate of about 456/100000 live births, far from the Sustainable Development Goal Agenda 2030. The Catholic Church remains one of the biggest suppliers of health care services in Cameroon and receives huge amounts of funding from donors, but their role in providing SRH care is restricted by religious norms. This study therefore uses semi-structured interviews with doctors from Catholic hospitals in the North-West region to explore their experiences in providing SRH in a conflict region. Qualitative coding was done with NVivo, and data analysed using thematic analysis. The respondents described strict rules and a broad range of challenges to providing comprehensive sexual and reproductive health care services. Nonetheless there is evidence of doctors overcoming obstacles to providing SRH care despite the religious and political climate. However, while attempting to overcome challenges, participants describe numerous examples of poor SRH care and poor health outcomes. The study highlights the importance of understanding the intersect between religion and women's health, particularly in improving access to SRH to vulnerable populations in conflict affected areas. It further provides insight into doctors' motivations in practicing medicine, and how doctors cope and make efforts to provide care and minimize harm. 


\section{BACKGROUND}

Sexual and reproductive health and rights (SRHR) are an intricate part of promoting gender equality, ensuring good health for all and are integral to achieving the Sustainable Development Goals (SDGs) especially goals 3, 4 and 5 (1). Accessing good quality SRHR services are essential to improving lives of women world-wide, particularly in Sub-Saharan Africa where there is a high burden of disease and mortality associated with limited access to SRHR (2). Reproductive health influences a woman's quality of life and lack of access to SRHR services can lead to unintended pregnancies, unsafe abortions, sexually transmitted infections, gender-based violence, disability and maternal death (3).

Faith-based health providers are organisations that deliver health services to their populations, but these services are underlined by principles and morals based on religious beliefs (4). Faith-based health providers have a long-standing history of providing health care to populations in many countries in Sub-Saharan Africa, where reports have estimated that this type of providers contribute about 30$70 \%$ of all health care (5). Faith-based health providers have been able to reach extended communities, assisting people most in need by complementing the services provided by the public health sector, and at the same time promoting their religion (6). They have also been involved in sexual and reproductive health care services especially providing family planning and HIV/AIDS (Human immune virus/Human immunodeficiency syndrome) services in Sub-Saharan Africa. For example, the Global Fund to Fight Aids, recognized the importance faith-based actors as partners and has channelled almost 2 billion dollars through these organizations to strengthen programs aimed at addressing AIDS, Tuberculosis and Malaria (7). Some reports have further claimed that about $25 \%$ of all HIV/AIDS related services in the world are provided by the Catholic church (8).

The Catholic church is one of the largest non-governmental provider of health in the world (6). However, all the institutions under the umbrella of the Catholic church need to serve the population in accordance with the norm and values of the church (9). These directives are very strict and allow little flexibility with regards to SRHR $(10,11)$. The Catholic church for example, forbids the use of all forms of modern contraception including sterilization and the use of condoms (12), and further forbid abortions when directly intended to end a pregnancy after conception (13). Moreover, Catholic health care services are prohibited from providing access to emergency 
contraceptives (14). Instead the Catholic church promotes abstinence for the unmarried and encourages fidelity among married couples as the only morally acceptable and most effective way of preventing sexually transmitted infections (15). The Catholic church does not support comprehensive sexual education, and argues that it is the right of the parents to educate their children on matters of sexuality, with emphasis on teachings which obey the moral obligations of its doctrine (10).

\section{Catholic health providers in Cameroon}

The Cameroonian health system is governed by the Ministry of Public Health. Health service is provided by the Public, Private and Traditional health care services (16). About $40 \%$ of health care delivery which is provided by the private sector is composed of faith-based actors, NGOs and private institutions (17). The Catholic Church plays a pivotal role in health service provision in Cameroon and provides about a third of all faith-based health care in the country (18). Faith-based health providers hold a good reputation in Cameroonian communities, in particular for their quality of care and compassionate service (19). Despite strict rules and norms surrounding SRHR, in the recent decade in Cameroon, faith-based health providers, including Catholic health providers have been engaged by donors in several sexual and reproductive health programmes (20). For example, Catholic health providers have been included in Performance Based Financing initiatives, funded by the World Bank that aim to increase access to sexual and reproductive health care, and HIV/AIDS programmes as well as midwifery training (21). In spite of this, SRHR indicators in Cameroon continue to be poor, with an unmet need for family planning at $23 \%$ and very high maternal mortality of $467 / 100000$ live births, far from the goal set by the SDG (23). There is also some evidence to suggest that SRHR efforts have not been successful at Catholic health providers in Cameroon (22). The North-West region of Cameroon where this study took place has been severely affected by conflict since 2016 (24). This conflict has further hampered access to health care services including SRHR as there has been growing need to provide healthcare to its population (25). Given these poor SRHR outcomes, the high unmet need and the continued programmatic support of Catholic hospitals, it remains important to understand delivery of sexual and reproductive health services at Catholic hospitals, particularly in conflict affect areas which have an additional limited access to healthcare. 


\section{Conceptual framing}

The conceptual framework that has guided this study is situated at the interface between gender and religion, particularly Catholicism, and health care provision in fragile health systems. The research explores and builds on research on tensions between Catholicism and sexual and reproductive health and posits these in a context where the health system is fragile due to conflict (11). Civil conflict has been shown to directly affect the health outcome of a population leading to poor health outcomes particularly in women. In regions with already fragile health care structures, conflict further exposes these weaknesses and leaves the population stranded. A study on post-war effects of conflict showed that long term death and disability as a result of direct and indirect causes of civil war disproportionately affects women and children (26). It draws on literature and builds on the idea that faith-based health care providers can reach communities in the context of conflict because they appear more flexible and manage to withstand the stress of the crisis $(26)(27,28)(29)$. In this research we explore this concept with specific focus on sexual and reproductive health care needs of women. This conceptual framework guided the following aim:

To explore the experiences of doctors when providing sexual and reproductive health care at Catholic hospitals in conflict affected region. 


\section{RESEARCH METHODS}

\section{Study design}

This is a qualitative study using semi-structured interviews to explore doctors' experiences in the delivery of sexual and reproductive healthcare at Catholic hospitals. The study was reported following the Consolidated Criteria for Reporting Qualitative Research (COREQ) (30).

\section{Study Setting}

Cameroon is a lower middle income country located in Central Africa and has a population of about 26,545,863 inhabitants (31). This bilingual (English-French) country is made of 10 administrative regions divided into 189 health districts (32). The English-speaking part constitute two of the 10 regions and makes up about $20 \%$ of the country's population (33). The population of Cameroon is made up of 38.4\% Catholic, 26.4\% protestant, $20.9 \%$ Muslim and about $14 \%$ other beliefs (33). The main health financing sources are the government, public enterprises, foreign aid donors, private enterprises, households, religious missions and non-governmental organisations (NGOs) (34).

This study was conducted in the North-West region of Cameroon, one of two Anglophone regions. The anglophone regions have been undergoing what is controversially known as the "Anglophone Crisis" characterised by civil protest, strikes, evolution of arm groups and militarization of the region till date (24). Reports by Human Right Watch have indicated that hundreds of thousands of civilians have been displaced and/or killed, including death of many of the armed separatist and military men since the beginning of the crisis (35). The crisis has caused destruction of many health care structures in an already fragile health care system leaving its population in the North-West region of about 2 million inhabitants (36) very vulnerable to disease and death (25). There are about 20 Catholic health providers in the North-West Region of Cameroon of which only a few have remained functional since the onset of the crises. These services have primary, secondary and tertiary health structures in the region (55). Three Catholic hospitals, which were still functional, were purposefully selected for this study based on them offering general consultation services, which included sexual and reproductive health care services such as maternal and childcare services to the population. The names of the hospitals are purposively omitted to protect the anonymity of the research participants. Cameroon as a case study was selected because it was accessible to the research team despite the fact that it is a conflict-affected area. 


\section{Study population and sampling}

Purposive sampling was used to select 10 medical doctors working at three different Catholic health care facilities. Selection criteria were general practitioners who have worked at a Catholic hospital for at least one year. General practitioners were selected because they have first-hand exposure to all patients who present at the hospital, including women seeking sexual and reproductive healthcare services. Specialist were excluded because the range of patients they saw were very specific and would not cover the scope of this paper. The participants included three females and seven male doctors available for the study and whose working experience ranged from two to seven years in Catholic hospitals. We reached the maximum number of participants at these hospitals. Selecting further sites was not possible due to security reasons.

\section{Data collection}

All interviews were conducted in English by AAF with the use of an interview guide (annex 1) within a six-week period. Some interviews were conducted over Zoom while others were done at the doctors' offices. Interviews lasted for approximately 40 minutes and were recorded using the cell phone and computer. The interviews were transcribed. Information was stored in the researcher's laptop and safely kept using a password known only by the principal investigator to ensure confidentiality of sensitive information.

\section{Data analysis}

Data was analysed using the principles of thematic analysis by Braun and Clark (37). The analysis began by transcribing the recorded data within 4 weeks after the interviews. The recorded data was listened to twice to ensure information was not lost and underlying meaning was represented in the transcription. The data was re-read, making notes of explanations.

Double open coding, by AAF and SHvW was done with the assistance of the NVivo version 12.0 (38). Initial coding involved analysing the meaning of text, including all data that were potentially relevant to the research aim into different or similar codes. The next stage of coding included recoding and rechecking original codes. After this, similar codes were grouped into subcategories, categories and themes. Later, the researchers had to re-examine and re-evaluate the themes and categories to make sure there was no overlapping of ideas and the interpretation within and between the themes were coherent. This led to some changes by looking for latent meaning of the data and resulted in merging, deleting, and renaming some of the subcategories and themes. After 
repeating this process a few times and ensuring that each theme had a distinct focus, were not repetitive and answered the research question, a final version of three themes were developed.

\section{Ethical consideration}

Ethical approval $(\mathbf{2 0 2 1} / \mathbf{2 9 2 H} / \mathbf{u b a} / \mathbf{I R B})$ was sought from the Ethical review board of the University of Bamenda, Cameroon to carry out this study. Permission was also sought from each hospital to allow the researcher to conduct interviews with their staff. All participants were informed of their rights to participate or not in the research project and their right to redraw at any moment during the duration of the project. All interviewees signed a written consent form and agreed to audio recording.

\section{Reflexivity}

During the research process, it is important that researchers are aware of their own role in carrying out the research and analysis and how this might influence the outcome of the study. AAF has previously worked as a doctor at a Catholic hospital, consequently the participants felt at ease and were open to discuss very sensitive issues with her. AAF also tried to ensure that the information collected was a true representation of participants' ideas by asking many follow-up questions for clarity. AAF also made a conscious effort of not expressing her own opinion during the interview and analysis process. Avoidance of personal bias was possible through regular reflections in a research diary and continuous discussion of progress and findings with the research team. 


\section{RESULTS}

The qualitative data analysis resulted in three major themes presented in table 1 .

\section{Sub-category}

\section{Category}

\section{Theme}

The institution's rules: SRHR at Catholic Rules

hospital

Atmosphere of fear

Navigating rules and dilemmas when providing $S R H R$

\section{Responsibility towards the patient and Dilemmas}

community (people want SRHR services!)

Responsibility towards the administration

Personal faith

$\begin{aligned} & \text { Administration agreeing to some } \\ & \text { procedures }\end{aligned}$
$\begin{aligned} & \text { Partnership with other hospitals or } \\ & \text { partners to find solutions } \\ & \text { organizations }\end{aligned}$

Referring patients

Advising patients

Doctors put patients first

Providing SRHR care in secret

Patient overload

Poor post rape care

Missed opportunities

Crisis effects
Unfortunate effects of

conflict

Unsatisfactory SRHR care

Tragedies and

Poor SRHR and outcomes

abandonment 


\section{Navigating rules and dilemmas when providing SRHR}

While working at Catholic hospitals, the doctors are expected to abide by the rules of the Church. This includes a ban on advising, prescribing, or performing any form of modern family planning within the hospital and a ban on the prescription of emergency contraceptives in the event of rape or incest. Abortions, although this is not only limited to Catholic hospitals in Cameroon, are also strictly prohibited, even in the case of medical necessity. Instead, if patients request information about family planning, they received counselling on the natural family planning method from a reverend sister:

...we see patients who come in for family planning, or just counselling on the reproductive health... you have a limited number of things that you can say to that patient, as a doctor working in a Catholic hospital. For example, like the Catholic Church pushes only for the natural method of contraception that is a woman knows her safe and unsafe days. (Interview 2)

Some of the doctors were told of these rules prior to their practice, while others were expected to learn about them during their practice. The strict rules and regulations affect the working environment, which the interviewees describe as an environment of fear from the religious hierarchy:

...I know many health personnel who shy away from interaction with the hierarchy. ... There is this fear. You're working with fear.... (Interview 1)

This environment of fear influences practice with regards to SRHR. Doctors have to navigate rules by the administration, best practices in medicine and what is best for their patient, as well as their own beliefs:

... it's very difficult to observe everything as a Catholic, or everything as a medical doctor. So you have to join between the two and know what is good for the patient. (Interview 3)

The doctors explained of receiving constant demands and desperate request from patients who need SRHR care and are not aware that these services are not provided at Catholic hospitals. These 
demands were mostly concerning emergency contraceptives in young adults and sterilisation for women with multiple children. In an example, where a woman with multiple previous caesarean section needed sterilization, the doctor felt that rejecting assistance could lead to subsequent very high-risk pregnancies and even death. These kinds of situations were troubling for many of the doctors, especially those who were Catholics, when trying to find a balance between their faith and moral duties to the patient.

it makes it difficult, you know, when you see someone who is in need, you see patients and because of some rules, you cannot cater to the patient. There is this saying the patient is the king. So do you tell the King Sorry, I cannot serve you. (Interview 4)

\section{Overcoming obstacles to providing SRHR care}

Yet, despite the rules and regulations regarding SRHR provision at Catholic hospitals, doctors find ways to navigate these challenges and manage to provide services to the best of their abilities. Three different ways of doing so emerged from the data analysis.

Firstly, doctors opt to refer patients to government hospitals or other hospitals that offer SRHR services that they cannot. Some Catholic hospitals were against referrals but have no way of monitoring referrals by doctors since these were done during consultations, whilst other Catholic hospitals considered referral an appropriate alternative.

The truth is that we are there for the patient. And if the hospital has a policy that they don't permit this contraceptive to be offered here. But you see that that patient needs it. So, I advise the patient that this is where you can get it, and this is where you can get a better management. (Interview 2)

Doctors would also refer victims of sexual violence to non-governmental or international organizations that provide emergency contraceptives.

The Church says you should not give the patient (emergency) contraception, but it doesn't say whether you should tell them about the availability of contraception. So, there's this grey area that you can manoeuvre. I can tell her 
that we cannot give but you can go somewhere ... it boils down to their choice whether they want to have it or not. (Interview 8)

Secondly, doctors have managed to cooperate with the Catholic hospital administration to assist patients. If the doctors could demonstrate potential direct risk to a woman's life if an intervention is not done, some administrations would agree to allow some interventions.

I've had a patient that has had an ectopic pregnancy on an intrauterine device. For the case of ectopic pregnancy, she was 46 years and she wanted to stop having children. ... So, in that case, I had to operate. And because of that, I advised the institution that it was better for us to do the tubal ligation [female sterilization]. After several conversations they finally accepted. (Interview 5)

However, such an approval was highly dependent on the administration involved as some of them would completely deny such requests.

A third way of overcoming challenges was repeatedly described as how doctors put patients first and provided SRHR without involvement of their institutions, in other words they would break the rules to help a patient. In some instances, the doctors would discuss with their colleagues' on ways to assist patients. This help came in the form of performing procedures within the hospital milieu in secrecy, advising patients on all the various options available for any SRHR services and/or referring patients to hospitals where they knew they could receive appropriate care.

You know, we have our own code. In as much as you are in a held institution, we have our small community as doctors, where we have situations, we first of all discuss among ourselves as doctors. (Interview 3)

Moreover, doctors mentioned that they mostly avoid conflict surrounding this topic and get on with their own role as a doctor:

You have to maybe act like you agree with the hierarchy but deep down you're the person in contact with the patient." (Interview 10) 


\section{Poor SRHR care and outcomes}

Even though doctors do their best to address SRHR needs at Catholic hospitals, they describe a high unmet need, suboptimal SRHR care and dangerous practices in the region affected by conflict.

Doctors describe very high unmet need for SRHR services which has worsened during the crisis in the North-West region, firstly as a result of less available functional hospitals, overcrowding of existing hospitals, and impoverishment of people due to conflict who are desperate to receive healthcare.

...the crisis has made everything worse. The people here don't have any money to pay for bills, it's not even safe for them to go to the farm to earn a living. Many of them in the other villages ran away including myself. All the hospital staff left. I heard my previous hospital is now a hiding spot for the fighters. It's very complicated (Interview 2)

With increased demand for and reduced access to health care, doctors describe several missed opportunities where a women could prevent more unwanted pregnancies. Such as immediately after delivery of a new baby, or post rape. The doctors believe that the availability of postnatal counselling for family planning could prevent the observed early repeated pregnancies:

Women are already pregnant again when they come to vaccinate their babies at eight weeks old. But now, you cannot do anything about it in the hospital. (Interview 9)

Moreover, even in cases where referrals could be seen as an option, doctors are concerned about missed opportunities for care due to the referrals they sometimes make for modern family planning, especially in times of conflict. The distance to the other hospitals, the long waiting times and limited availability of contraceptives begs the question whether they get access to these services despite referrals. This becomes even more frustrating when it comes to appropriate post rape care which is time dependent. 
... after rape, there's a timeframe in which you needs to take the medication, so when they come to us, by the time we're done all the tests, talking to them, making them feel better, and referring them to pharmacy, it takes a very long time, sometimes they don't even want to leave when they come to the hospital, they spend hours and hours crying, we might have to find a family member who will need to go and buy the medications. If it [emergency contraception] was readily available, something that the moment they come and they've been raped that's the first they should take coz it depends on the hours, right? That was one of the times that Yeah, I wish I really used to feel like we could have done more. (Interview7)

Doctors further describe challenges around providing SRHR care in secrecy. This poses a problem especially regarding recording of patient medical history. In extreme cases, they exaggerate or falsify medical records to justify reasons to provide some services such as sterilization. While at other times, they carry out procedures and do not record them in the file to avoid getting caught by the administration.

... Um, yeah, they had like, for example, there are cases where because there are some reverend sisters [nuns in charge of the hospital] who when they are present in the theatres know exactly what we're doing. And the woman really, really wants bilateral tubal ligation [female sterilization]. So, we just discussed with our colleagues and discuss with a patient, and we'll be like, okay, you said you had three surgeries, just say you have four surgeries, we would write that in your book so that the sisters can allow us to do this for you. (Interview 8)

Doctors further describe the challenges with managing the implications, such as what if a patient changes their mind and decides to report to the administration on their secret activities. Moreover, they have to communicate with each other to ensure that continuity of care can be provided, especially since medical records cannot include certain information. 
... the rest of us have to know what was done because we sometimes follow up the same patient and we need to have the same language in front the sisters right? So that we don't tell one sister something and then other doctors say actually this patient didn't go through this procedure and you get in trouble. (Interview6)

The doctors describe that the consequences of not freely providing SRHR are not always optimal. It can lead to anger, and frustrations during work especially if a patient loses their life over a preventable cause. In the words of a doctor:

There was an incident that happened with a girl who was pregnant. She was about 19years old and wanted to do a pregnancy test. Unfortunately for her there was a reverend sister there, she did a test the reverend sister refused to tell her the results and told her to call her parents. So this girl refused to make the call, got desperate and left ... I don't know what she did... this lady came back to the hospital about a week later, and had developed sepsis... she had an unsafe abortion... And we couldn't save her life. (Interview 10) 


\section{DISCUSSION}

This study focuses on the experience and perceptions of doctors in providing sexual and reproductive healthcare in Catholic Hospitals in conflict affected areas in Cameroon. The findings echoes previous literature pointing to the challenges of provision of SRHR at faith-based health providers $(39,40)$. For example, a reproductive health programme in Burkina Faso, examined the effect of faith-actor engagement on gender inequality and health it was found that the faith-actors did not provide condoms (41). Moreover, in the context of the studied community, it is socially acceptable for men to have extra-marital affairs but not for women. The faith-actors do not account for these gender imbalances, which leave women more vulnerable to unwanted pregnancies and sexual transmitted infections, including HIV/AIDS (41).

This study further shows that doctors disagree with strict hospital policies about SRHR and continually face dilemmas where they have to balance the needs of the patients, regulations of the hospital and personal beliefs. Just as in other studies, health care workers in faith-based hospitals do not always agree with hospital policy, and often face very difficult ethical decisions in their patient management $(40,43)$. This sometimes causes distress to them especially when they feel the patients outcome is a direct consequence of their actions $(44,45)$.

One of the core findings of this study is that doctors find ways to overcome the barriers to providing sexual and reproductive health services at Catholic hospitals. Whilst this is a promising finding and arguably increases women's access to the services they need, there are many problems with clandestine provision of sexual and reproductive healthcare. This is problematic in a setting where resources are scarce and it takes time to find ways to provide the services without involving the administration (16). It also complicates issues such as health record management, which could pose problems if post-operative complications emerge. Moreover, referral of patients may be the solution that doctors highlight but given the challenges with regards to transportation in the NorthWest region and the insecurity linked to moving around it is likely that women were unable to seek public services that offer the sexual health services they would have required $(25,46)$.

Consequently, the finding that doctors continuously observed poor sexual and reproductive health outcomes including inability to provide emergency contraception on time, inability of advising 
young women on family planning, witnessing of backstreet abortions and the consequences thereof is not surprising, and similar to those made in Cameroon (47)(48).

The results from this study highlight there is a treatment gap for SRHR needs, and that Catholic values on SRHR undermine this. This finding is important in light of the fact that donors invest substantially in faith-based health providers in Cameroon (20,22). It is also an important finding in light of the growing treatment gap as a result to enduring conflict in the region. Whilst we do not argue for a discontinuation of donor investment, we argue for more dialogue on this topic and exploration of solutions, particularly in times of conflict where resources are scarce and SRHR needs are especially high. For example, referrals appear to be an acceptable solution (although not always) for Catholic hospitals, however, these are currently expensive, not systematic and without follow up. Systematic and specific collaborations between Catholic and public hospitals, or between Catholic hospitals and non-governmental actors that provide services such as emergency rape care should be encouraged. We also suggest that doctors receive guidance and support on the issue of facing dilemmas at the interface between religion and medicine as described in this study as part of their medical education.

A further important finding is that despite the fact that the conflict requires adaptation and responses to growing needs for women's health, the results in this study show that adaptation does not happen in this case study, and Catholic norms and values prevail. This is contrary to previous literature where faith-based health care providers have shown to be more resilient in providing health care especially during conflict, and complement the activities of the public sector $(27,28)$. A study carried out in Ghana, Malawi, DRC and Sudan, for example, showed that faith-based health care providers play a major role in strengthening the health care system and are able to withstanding the stress as a result of crises $(38,40)$. The results from our study show that although Catholic hospitals are important in the context of a conflict, they do not address specific sexual and reproductive health needs of vulnerable women. 


\section{CONCLUSION}

This study shows that doctors try to overcome barriers to providing SRH care at Catholic hospitals. However, doctors remain frustrated with treatment dilemmas and witnessing of poor health outcomes, tragedies and missed opportunities. Women further lose out to urgent needs SRH services. The findings from this study show that innovative solutions need to be tested to address both doctor's difficult position and a missed opportunity for much needed sexual and reproductive healthcare, particularly in conflict affected areas. 


\section{LIST OF ABBREVIATIONS}

SRH: $\quad$ Sexual and Reproductive Health

SRHR: $\quad$ Sexual and Reproductive Health Rights

RH: $\quad$ Reproductive Health

SDG: $\quad$ Sustainable Development Goals

FBPs: $\quad$ Faith-Based Organizations

WHO: World Health Organization

SSA: $\quad$ Sub-Saharan Africa

HIV/AIDS: Human Immune Deficiency Virus/Acquired Immune Deficiency Syndrome 


\section{DECLARATIONS}

Ethics approval and consent to participate

Ethical approval (2021/292H/uba/IRB) was sought from the Ethical review board of the University of Bamenda, Cameroon to carry out this study.

\section{Consent for publication}

NA

\section{Availability of data and materials}

The datasets generated and/or analyzed during the current study are not publicly available due sensitive nature of contents and confidentiality but are available from the corresponding author on reasonable request.

\section{Competing Interest}

The authors declare there was no conflicting interest.

\section{Funding}

No funding associated

\section{Authors contributions}

AAF wrote the background, methods, conducted the interviews, transcribed and analyzed the data and contributed to results and discussion.

MDS revised the background, methods, results and discussions

ECL revised the background, methods, results and discussions

SHW analyzed the data and wrote the results and discussion and revised the background and methods.

\section{ACKNOWLEDGMENT}

Special thanks and appreciation to all the doctors in the various hospitals who participated in this research. 


\section{References}

1. Ravindran TKS, Govender V. Sexual and reproductive health services in universal health coverage: a review of recent evidence from low- and middle-income countries. Sex Reprod Health Matters. 2020 Dec 17;28(2):1779632.

2. Refugees UNHC for. Sexual and Reproductive Health [Internet]. UNHCR. [cited 2021 Apr 29]. Available from: https://www.unhcr.org/reproductive-health.html

3. Say L, Chou D, Gemmill A, Tunçalp Ö, Moller A-B, Daniels J, et al. Global causes of maternal death: a WHO systematic analysis. Lancet Glob Health. 2014 Jun 1;2(6):e323-33.

4. Bielefeld W, Cleveland WS. Defining Faith-Based Organizations and Understanding Them through Research Symposium. Nonprofit Volunt Sect Q. 2013;42(3):442-67.

5. WHO | Faith-based organizations play a major role in HIV/AIDS care and treatment in sub-Saharan Africa [Internet]. WHO. World Health Organization; [cited 2021 Apr 29]. Available from: https://www.who.int/mediacentre/news/notes/2007/np05/en/

6. Benn C. Guest introduction: faith and health in development contexts. Dev Pract. 2017 Jul 4;27(5):575-9.

7. The Global Fund and the Private Sector: Partnerships for Better Health [Internet]. Friends of The Global Fight. 2017 [cited 2021 Feb 15]. Available from: https://www.theglobalfight.org/global-fundprivate-sector-partnerships-better-health/

8. Catholics Provide More Than 25\% Of HIV/AIDS Care Worldwide [Internet]. Caritas Latinoamerica. 2014 [cited 2021 May 9]. Available from: https://caritaslatinoamerica.org/catholics-provide-morethan-25-of-hiv-aids-care-worldwide/

9. Thorne NB, Soderborg TK, Glover JJ, Hoffecker L, Guiahi M. Reproductive Health Care in Catholic Facilities: A Scoping Review. Obstet Gynecol. 2019 Jan;133(1):105-15.

10. ethical-religious-directives-catholic-health-service-sixth-edition-2016-06.pdf [Internet]. [cited 2021 Apr 13]. Available from: https://www.usccb.org/about/doctrine/ethical-and-religiousdirectives/upload/ethical-religious-directives-catholic-health-service-sixth-edition-2016-06.pdf

11. Richards E. The Catholic Church and reproductive health and rights in Timor-Leste: contestation, negotiation and cooperation. Cult Health Sex. 2015 Mar 16;17(3):343-58.

12. Schenker JG. Women's reproductive health: monotheistic religious perspectives. Int J Gynecol Obstet. 2000;70(1):77-86.

13. Barry R. The Roman Catholic position on abortion. Adv Bioeth. 1997;2:151-82.

14. Bucar L, Nolan D. Emergency contraception and Catholic hospitals. Conscience Wash DC. 1999;20(1):20-2. 
15. Coates AL, Hill PS, Rushton S, Balen J. The Holy See on sexual and reproductive health rights: conservative in position, dynamic in response. Reprod Health Matters. 2014 Jan;22(44):114-24.

16. Tandi TE, Cho Y, Akam AJ-C, Afoh CO, Ryu SH, Choi MS, et al. Cameroon public health sector: shortage and inequalities in geographic distribution of health personnel. Int J Equity Health [Internet]. 2015 May 12 [cited 2021 Apr 25];14. Available from: https://www.ncbi.nlm.nih.gov/pmc/articles/PMC4440287/

17. Olivier J, Wodon Q. Playing broken telephone: assessing faith-inspired health care provision in Africa. Dev Pract. 2012 Aug 1;22(5-6):819-34.

18. Wees SH van, Betsi E, Sop MDS. A description and explanation of the complex landscape of faithbased organisations in Cameroon's health sector. Dev Pract. 2021 Apr 3;31(3):356-67.

19. Boulenger D, Criel B. The difficult relationship between faith-based health care organisations and the public sector in sub-Saharan Africa: the case of contracting experiences in Cameroon, Tanzania, Chad and Uganda [Internet]. ITGPress; 2012 [cited 2021 Apr 13]. Available from:

https://research.itg.be/en/publications/the-difficult-relationship-between-faith-based-health-careorgani

20. van Wees $\mathrm{SH}$, Jennings $\mathrm{M}$. The challenges of donor engagement with faith-based organizations in Cameroon's health sector: a qualitative study. Health Policy Plan. 2021 May 1;36(4):464-72.

21. Wees S, Maturin Desire SS, Betsi E, Olongo S, Jennings $M$. The role of faith-based health professions schools in Cameroon's health system. Glob Public Health. 2020 Oct 6;16:1-16.

22. Herzig Van Wees S. "Hidden Catholics", "faith-blind" donors and "FBO empires" : a mixed-methods study on donor engagement of faith-based organisations in the Cameroonian health system [Internet] [phd]. SOAS University of London; 2019 [cited 2021 Oct 26]. Available from: https://eprints.soas.ac.uk/32299/

23. Cameroon Demography and Health Survery 2018 [Internet]. [cited 2021 Oct 25]. Available from: https://dhsprogram.com/pubs/pdf/SR266/SR266.pdf

24. Pommerolle M-E, Heungoup HDM. The "Anglophone crisis": A tale of the Cameroonian postcolony. Afr Aff. 2017 Jul 1;116(464):526-38.

25. Nwati MT. The Anglophone Crisis: The Rise of Arms Trafficking and Smuggling, its Effects on the Two English Regions of Cameroon. Adv Appl Sociol. 2021 Jan 26;11(01):1.

26. Ghobarah HA, Huth P, Russett B. The post-war public health effects of civil conflict. Soc Sci Med. 2004 Aug 1;59(4):869-84.

27. Seay LE. Effective responses: Protestants, Catholics and the provision of health care in the post-war Kivus. Rev Afr Polit Econ. 2013 Mar 1;40(135):83-97.

28. Whyle E, Olivier J. Models of engagement between the state and the faith sector in sub-Saharan Africa - a systematic review. Dev Pract. 2017 Jul 4;27(5):684-97. 
29. Maulit JA. Partnerships that support health systems resilience over time: a study of non-state, faithbased health providers in Africa. 2017 [cited 2021 Oct 25]; Available from:

https://open.uct.ac.za/handle/11427/25455

30. ISSM_COREQ_Checklist.pdf [Internet]. [cited 2021 May 7]. Available from: http://cdn.elsevier.com/promis_misc/ISSM_COREQ_Checklist.pdf

31. Cameroon Demographics 2020 (Population, Age, Sex, Trends) - Worldometer [Internet]. [cited 2021 Apr 28]. Available from: https://www.worldometers.info/demographics/cameroon-demographics/

32. alliancehpsr_cameroon_abridgedprimasys2018.pdf [Internet]. [cited 2021 May 7]. Available from: https://www.who.int/alliance-hpsr/projects/alliancehpsr_cameroon_abridgedprimasys2018.pdf

33. BUCREP - Résumé - Etat et Structures de la popualtion [Internet]. [cited 2021 Apr 28]. Available from: http://www.bucrep.cm/index.php/fr/recensements/3eme-rgph/resultats?id=125

34. Maturin Désiré Sop Sop. Epidemiological description of smear-positive tuberculosis in Bafoussam Town. [Yaounde]: University of Yaoundé I,; 2017.

35. Cameroon: Civilians Killed in Anglophone Regions [Internet]. Human Rights Watch. 2020 [cited 2021 Oct 25]. Available from: https://www.hrw.org/news/2020/07/27/cameroon-civilians-killedanglophone-regions

36. North-West Region - Welcome [Internet]. [cited 2021 Apr 28]. Available from: http://www.northwest-cameroon.com/home-35-front-0.html

37. Braun V, Clarke V. Using thematic analysis in psychology. Qual Res Psychol. 2006 Jan 1;3(2):77-101.

38. Qualitative Data Analysis Software | NVivo [Internet]. [cited 2021 Apr 18]. Available from: https://www.qsrinternational.com/nvivo-qualitative-data-analysis-software/home

39. Stulberg DB, Guiahi M, Hebert LE, Freedman LR. Women's Expectation of Receiving Reproductive Health Care at Catholic and Non-Catholic Hospitals. Perspect Sex Reprod Health. 2019;51(3):135-42.

40. Stulberg DB, Lawrence RE, Shattuck J, Curlin FA. Religious hospitals and primary care physicians: conflicts over policies for patient care. J Gen Intern Med. 2010 Jul;25(7):725-30.

41. Marshall M, Taylor N. Tackling HIV and AIDS with faith-based communities: learning from attitudes on gender relations and sexual rights within local evangelical churches in Burkina Faso, Zimbabwe, and South Africa. Gend Dev. 2006 Nov 1;14(3):363-74.

42. Nunn A, Miller K, Lapert H, Ellertson C. Contraceptive emergency: Catholic hospitals overwhelmingly refuse to provide EC. Conscience Wash DC. 2003;24(2):38-41.

43. Stulberg D, Freedman L. Tubal sterilization in catholic hospitals: the rules and realities from ob/gyns' perspectives. Contraception. $2012 \operatorname{Sep}$ 1;86(3):322.

44. Sepper E. Not Only the Doctor's Dilemma: The Complexity of Conscience in Medicine. 2012 Dec 30; 
45. Freedman LR, Stulberg DB. Conflicts in Care for Obstetric Complications in Catholic Hospitals. AJOB Prim Res. 2013;4(4):11.

46. Saidu Y, Vouking M, Njoh AA, Bachire HB, Tonga C, Mofor R, et al. The effect of the ongoing civil strife on key immunisation outcomes in the North West and South West regions of Cameroon. Confl Health. 2021 Dec;15(1):1-8.

47. Maternal mortality ratio (modeled estimate, per 100,000 live births) - Cameroon | Data [Internet]. [cited 2021 Oct 18]. Available from:

https://data.worldbank.org/indicator/SH.STA.MMRT?locations=CM

48. Agejo PA. Legal Framework to Gender-Based Violence, Sexual and Reproductive Health Rights of Indigenous Women in Cameroon. Afr J Leg Stud. 2019 Dec 10;11(4):371-87. 